\title{
Peculiarities of communicative behavior of the Chechen: emotional component
}

\author{
Isita Muskhanova ${ }^{1, *}$, Fatima Bazaeva $^{2}$, Lalita Djamalkhanova $^{2}$, Tatyana Yussupkhadjieva $^{2}$ \\ ${ }^{1}$ Academy of Sciences of the Chechen Republic, Grozny, Russia \\ ${ }^{2}$ Chechen State Pedagogical University, Grozny, Russia
}

\begin{abstract}
The article analyzes the features of Chechen communicative behavior in the context of the emotional component. It is noted that selfcontrol dominates in the traditional communicative behavior of Chechens. Free expression of emotions in Chechen society is perceived as inappropriate, and suppression of emotions is characteristic of both men and women and belongs to one of the advantages of the Chechen mentality. It is concluded that the key idea of the communicative picture of the world of the Chechens is manifested in the model "yakh hilar - yukh lar yar" (honor to have - to keep a face), which determines their worldview and morality. The end-to-end line, expressing the emotional component of the communicative behavior of the Chechens - "sobar" (restraint, self-control)), considered in the following directions: everyday life - family, society - social etiquette, rituals - ritual etiquette).
\end{abstract}

\section{Introduction}

The relevance of issues related to communicative behavior is due to the importance of national and cultural specifics in interethnic communication. According to the definition given in the work of I.A. Sternin, "national communicative behavior is a set of norms and traditions of communication of a certain linguocultural community, which means a people united by language and culture; unity of the people, their language and culture" [1].

The problem of communicative behavior is very relevant at the present time. Many scientists are working in this direction, studying communicative behavior in various social, ethnic, age groups. is also worth noting the work of such researchers as Barry M. Prizant Ph.D. Amy M. Wetherby Ph.D. [3], Jeffrey A. Atlas Leah Blumberg Lapidus [4], William D. Frea, Carolyn Hughes [5], Inger Dybdahl Sørby Oystein Nytro [6]. Thus, the work of the Swedish researcher Marja-TerttuTryggvason, who took part in a project to study the communicative behavior of three northern peoples, is of interest. According to her research, Swedish families are more talkative. unlike Finnish and mixed Swedish-Finnish [7]. A longterm prospective study of the communicative behavior of adults and children was carried out by scientists at the University of Florida in the USA S. A. M. Kloth P. Janssen F. W. Kraaimaat G. J. Brutten. [8], William T.Rogers [9], Yeunjae Lee [10], Laura Boundy Thea Cameron-Faulkner Anna Theakston [11], S. A. M. Kloth P. Janssen F. W. Kraaimaat G. J. Brutten [12], Catherine Lord ph.d. Andrew Pickles Ph.D. [13].

\footnotetext{
*Corresponding author: vinter_65@mail.ru
} 
In the course of numerous meetings with representatives of African American and Korean migrants in Los Angeles, Benjamin Baley observed the communicative behavior of two ethnic groups in Los Angeles, not knowing the rules of conduct and etiquette adopted in a particular community leads to misunderstandings, as well as to the inevitable conflicts [14]. A group of scientists conducted a study at one of the Kazakhstani universities (Suleyman Demirel University) aimed at studying the awareness of pre-professional teachers about the variations of verbal and non-verbal communicative behavior of Kazakhs and Americans. In their work, they came to the conclusion that teachers are aware of differences in communication culture, as verbal, and non-verbal, Kazakhs and Americans [15].

He features of the communicative behavior of representatives of a particular ethnic group are associated with the emotional component. The degree of emotional openness and expressiveness of ethnophores determines the functions of emotions in communication. Emotions are associated with individual psychological characteristics and a person's belonging to a particular ethnic culture. Each nation has developed models of communicative behavior in the process of historical development. The experience and manifestation of individual emotions by an individual is associated with social connotation and sociocultural context. Thus, the semantic realization in the structure of emotional vocabulary, social organization and the communicative picture of the world, reflected in the minds of representatives of various national communities, depends on the emotional component of communication.

\section{Discussion}

Despite the common historical development of the North Caucasian peoples, the models of Chechen communicative behavior are based on specific mental characteristics. As an illustration, one should pay attention to the fact of restraint in the manifestation of emotions among Chechens, despite a certain expressiveness characteristic of the representatives of this ethnic group. Self-control dominates in the traditional communicative behavior of Chechens, and the free expression of emotions in Chechen society is perceived as inappropriate. It should be noted that the suppression of emotions is characteristic of both men and women and belongs to one of the advantages of the Chechen mentality. Restraint in the expression of emotions to representatives of the Chechen ethnos is especially vivid under conditions of a sociocultural crisis [2].

The traditional system of communicative behavior of Chechens is conditioned by the peculiarities of the socio-economic, cultural, and political development of the ethnic group. The socio-cultural context continues to exert tremendous development on the emotional component of the communicative behavior of the Chechens. The family is the basis of spirituality, morality, emotional and personal development of a person. The credo of the Chechen family's upbringing can be expressed as follows: "imanan, giillakhan, khekalan, khetaman bukh zhimalliyn tiekan tiekan tiekh bu" (faith, politeness, intellect, consciousness is laid in childhood), i.e. spirituality and morality come from childhood. The model of communicative behavior of the Chechens is based on this principle, which forms the dignity of the individual and determines his mental characteristics. From the first stages of socialization, a person in Chechen society comprehends the basics of communicative behavior, comparing his consciousness (khetam) with the consciousness of another in communication, cognition of oneself as another and another as oneself occurs, which determines the self-development of the consciousness of the individual and ensures constant spiritual enrichment.

The key idea of the Chechens' communicative picture of the world is manifested in the expression "yakh hilar - yukh lar yar" (to have the honor - to keep the face), which determines their perception of the world and morality. The motivator of the emotional and intellectual 
activity of a Chechen personality is "yakh", it is quite difficult to translate this concept, the following moral and moral categories can serve as an analogue in Russian: "honor", "dignity", "inner pride", "inner nobility". Acts and deeds performed by a person for the benefit of other people, in the name of their salvation, without thinking about the consequences, without waiting for gratitude and praise are the essential characteristics of "yakh". The core components of the structure of the concept of "yakh" in the Chechen linguistic culture reflect the following semantic series - "mayralla" (courage), "donalla" (will), "siynozdangalla" (nobility), "kinkhetam" (kindness), "komarshalla" (generosity). "Yakh" in Chechen communicative behavior shows a pronounced sense of personal dignity, which, in our opinion, is conditioned by the historical aspect of the development of Chechen society. The absence of class distinctions among the Chechens contributed to the formation of a free, emancipated personality, recognizing only the power and might of the Almighty and ethnocultural values that regulate the model of behavior. In communicative behavior, a Chechen takes into account every detail of communication, since "dosh" (word) for a Chechen is a mental expression characterizing the presence or absence of "yakh"

A cross line expressing the emotional component of the communicative behavior of Chechens is "sobar" (restraint, self-control), which we consider in the following directions: everyday life - family, society - social etiquette, rituals - ritual etiquette). Restraint in communication is characteristic of Chechens in the bosom of the family. Traditionally, the Chechen society was characterized by a large, multi-generational family, uniting representatives of different generations. This caused the fact that young parents, husband and wife were reticent in the presence of their elders. As a rule, the daughter-in-law did not name her father-in-law, mother-in-law, brothers, sisters and other relatives of her husband. The mother did not call the first child by name and gave him another name, which was assigned to him for life. It was considered indecent for a young woman to call her first child by name, revealing her parents and other senior family members. Spouses, in the presence of their elders, practically do not communicate with each other, do not show emotions in relation to their own children. This model of communicative behavior is learned by children from an early age.

The social etiquette of Chechens also presupposes restraint in communication and behavior. In communicative behavior in society, it is unacceptable to interfere in someone else's conversation until asked. In the past, until about the 2000s, people in Chechen villages gathered for a "pkhogan" (spontaneous, unregulated gathering), at which both social and personal problems were discussed. "Pkhogan" assumed certain rules, representatives of the older generation gathered in the center; the youth listened attentively to the elders at a distance and did not interfere with the conversation. Whatever problems were discussed, young people would not interrupt their elders, much less argue with them.

Chechens communicative behavior is characterized by the strict adherence to the rules for organizing communication: consistency, delineation of certain specific situations in accordance with the age of the communicant, as well as speech etiquette formulas. One of the highest principles of Chechens' communicative behavior is respect for elders. It should be noted that in the speech etiquette of the Chechens there is no reference to "you" by name and patronymic. In appropriate situations, the Chechens, referring to elderly people, strangers, non-native and even strangers, use the following speech formulas: "Vokha stag" (old man), "Yokha stag" (old woman), "Vasha" (Uncle), "Detsa" (Aunt), and when referring to the younger generation - "Your" (Brother), Yisha (Sister), "Kant" (Son), "Yoa" (Daughter). A benevolent, warm attitude towards the others in the communicative behavior of the Chechens forms a culture of communication and a respectful attitude towards people. In addition, it should be noted the specificity of the verbal gratitude of the Chechens, according to which it is not customary in the family or in the friends circle to thank for the help, it is taken for granted. Charity, assistance to loved ones, those in need is enhanced during the 
period of difficult, crisis moments. Here, in our opinion, it is appropriate to give an example, when during a pandemic in medical clinics in Grozny, strangers paid for computed tomography of the lungs for patients. Help for needy relatives is provided not only by close relatives, but also by strangers who have a material opportunity. Therefore, for Chechens, help is a natural manifestation of good intentions, and does not need gratitude.

The ritual communicative behavior of Chechens presupposes an appropriate form of clothing, posture, and verbalization of thoughts. So, at the funeral, men and women gather separately. When expressing condolences, women can cry loudly and this is not condemned. Men - Chechens are restrained, even if a loved one died (father, mother, brother, sister, child), they hide their pain, do not show tears in public. One of the long-standing traditions is not to go full to a funeral, clothes should be modest, you should not show your contentment, adherence to this formal marker allows you to show sincere sympathy.

\section{Conclusions}

Non-verbal communication (gestures, facial expressions) add expressiveness to communication. They contribute to the transmission and perception of nuances and shades of thoughts, feelings, moods of communicants.

The ethnic and cultural specificity of the emotional component gives color and specificity to Chechen communicative behavior.

Studying the characteristics of Chechen communicative behavior is of great importance in the practice of intercultural communication.

\section{Acknowledgment}

This work is supported by the Russian Foundation for Basic Research, project 18-412200001 "Research models of communicative behavior of bilingual Chechens"

\section{References}

1. I.A. Sternin, Russian and Finnish communicative behavior (Publishing house of VSTU, Voronezh, 2000)

2. I.V. Muskhanova, Socio-cultural crises and the formation of an ethnocultural personality. Monograph (Publishing house of the State National University of the Academy of Sciences of the Chechen Republic, Grozny, 2011)

3. https://www.sciencedirect.com/science/article/abs/pii/S0890856709657221

4. https://www.sciencedirect.com/science/article/abs/pii/0021992488900123

5. https://onlinelibrary.wiley.com/doi/abs/10.1901/jaba.1997.30-701

6. https://www.sciencedirect.com/science/article/abs/pii/S1386505609001270

7. https://www.sciencedirect.com/science/article/abs/pii/S0378216606000312

8. https://www.sciencedirect.com/science/article/abs/pii/0021992479900480

9. https://www.sciencedirect.com/science/article/abs/pii/S0363811119301092

10. https://www.sciencedirect.com/science/article/pii/S0163638315301272

11. https://www.sciencedirect.com/science/article/abs/pii/0094730X95000275

12. https://www.sciencedirect.com/science/article/abs/pii/S0890856709664169

13. https://journals.sagepub.com/doi/abs/10.1177/0957926500011001004

14. https://www.sciencedirect.com/science/article/pii/S1877042814013159 